\title{
Mesenchymal stem cells promote endothelial progenitor cell proliferation by secreting insulin-like growth factor-1
}

\author{
JIXUE HOU ${ }^{1,2}$, XINYU PENG $^{2}$, JING WANG $^{3}$, HONGWEI ZHANG $^{2}$, JIE XIA $^{2}$, \\ QUANHU GE ${ }^{2}$, XIAOYI WANG ${ }^{2}, X_{\text {XULING } \mathrm{CHEN}^{4} \text { and XIANGWEI WU }}^{2,5}$ \\ ${ }^{1}$ Department of Hepatic Surgery, Tongji Hospital, Tongji Medical School, Huazhong University of Science and Technology, \\ Wuhan, Hubei 430030; ${ }^{2}$ Department of General Surgery; ${ }^{3}$ Out-Patient Department, First Affiliated Hospital; \\ ${ }^{4}$ Department of Immunology; ${ }^{5}$ Laboratory of Translational Medicine, School of Medicine, \\ Shihezi University, Shihezi, Xinjiang 832008, P.R. China
}

Received May 11, 2016; Accepted April 6, 2017

DOI: $10.3892 / \mathrm{mmr} .2017 .6741$

\begin{abstract}
Bone marrow mesenchymal stem cells (MSCs) and endothelial progenitor cells (EPCs) interact with each other. EPCs are able to promote the self-renewal of MSCs as niche cells in murine bone marrow, and MSCs are able to promote EPC proliferation in vitro in a co-culture system. It has previously been reported that MSCs can secrete insulin-like growth factor-1 (IGF-1), which serves critical functions in EPC proliferation. However, the mechanism underlying the IGF-1-mediated proliferation of EPCs remains unclear. The aim of the present study was to reveal the molecular mechanisms regulating this process. The effects of IGF-1, which is secreted by MSCs, on EPC proliferation via the PI3K/Akt signaling pathway were examined by MTT assay, reverse transcription-quantitative polymerase chain reaction and western blot analysis. The present study treated EPCs with various concentrations of IGF-1. The results demonstrated that IGF-1 significantly induced the proliferation of cultured EPCs. However, this effect was offset by treatment with the phosphatidylinositol 3-kinase (PI3K) inhibitor LY294002. These results indicated that the pro-proliferative effects of IGF-1 are mediated in response to the $\mathrm{PI} 3 \mathrm{~K} /$ protein kinase $\mathrm{B}$ signaling pathway.
\end{abstract}

Correspondence to: Professor Xiangwei Wu, Department of General Surgery, First Affiliated Hospital, School of Medicine, Shihezi University, 107 North 2nd Road, Shihezi, Xinjiang 832008, P.R. China

E-mail:wxwshz@126.com

Professor Xueling Chen, Department of Immunology, School of Medicine, Shihezi University, 107 North 2nd Road, Shihezi, Xinjiang 832008, P.R. China

E-mail: xuelingch@hotmail.com

Key words: mesenchymal stem cells, endothelial progenitor cells, insulin-like growth factor-1, proliferation, phosphatidylinositol 3-kinase/protein kinase B signaling pathway

\section{Introduction}

Mesenchymal stem cells (MSCs) are adult stem cells predominantly derived from bone marrow. MSCs have strong replicative capabilities and multidirectional differentiation potential. These stem cells can differentiate into chondrocytes, osteoblasts, adipocytes and muscle cells $(1,2)$. Under normal circumstances, MSCs settle in a specialized microenvironment termed stem-cell niche. When the body reacts to stimuli, including trauma or tumors, MSCs leave the stem-cell niche to achieve tissue reconstruction via directional migration, proliferation and differentiation (3-5).

Endothelial progenitor cells (EPCs) derived from the mesoderm have been identified as exhibiting high proliferative and self-renewal capabilities. EPCs have also been demonstrated to differentiate into vascular endothelial cells (6). EPCs are involved in the formation of neovessels in sites of vascular injury, including endothelial denudation and cardiac ischemia $(7,8)$.

Our previous studies demonstrated that, when MSCs were injected into the murine marrow cavity, increased adhesion occurred between MSCs and bone marrow sinuses. The MSCs primarily adhered to cluster of differentiation (CD) $31^{+}$vascular EPCs resulting in the formation of cell clusters. This finding was further confirmed by in vitro culture. In addition, our studies revealed that MSCs and EPCs were able to promote the proliferation of each other; however, the underlying mechanism remains unclear $(9,10)$.

In vitro studies have demonstrated that MSCs can secrete insulin-like growth factor 1 (IGF-1) $(11,12)$. IGF-1 is the main growth factor involved in the proliferation of numerous cell types, including myoblasts and epithelial cells $(13,14)$. The mitogenic action of IGF-1 on others cells is essential and mediated by the phosphatidylinositol 3-kinase (PI3K)/protein kinase B (Akt) signaling pathway, which is involved in cell cycle progression and cell survival $(15,16)$. To determine the regulatory effects of IGF-1 on the promotion of EPC proliferation by MSCs, and the possible molecular mechanism underlying this promotion, the present study initially investigated whether MSCs and EPCs secrete IGF-1, and then analyzed how IGF-1 influenced EPC proliferation via the PI3K/Akt signaling pathway. 


\section{Materials and methods}

Animal preparation and cell culture. All animals were maintained in the Animal Facility of Shihezi University (Shihezi, China) with sawdust as nesting material under controlled laboratory conditions (temperature, $20^{\circ} \mathrm{C} ; 12 \mathrm{~h}$ light $/ 12 \mathrm{~h}$ dark cycle with lights off at 8:00 p.m.; $55 \pm 5 \%$ humidity), and free access to food and water. A total of 40 male C57BL/6 J mice (wild-type; weight, 28-35 g; age, 6 weeks), were purchased from Xinjiang Medical University (Urumqi, China), and were used as cell sources. The same technique was used to harvest and culture all cell types; however, different materials and culture media were used. Third-generation cells were used in the experiments. The present study was approved by the Medical Ethics Committee of the First Affiliated Hospital, School of Medicine, Shihezi University.

Isolation and culture of murine bone marrow MSCs. Bone marrow MSCs were isolated using a technique reported in our previous study $(9,17)$. Briefly, bone marrow cells were collected from 6-week-old wild-type C57BL/6 male mice euthanized by cervical dislocation. The cells were cultured in low-glucose Dulbecco's modified Eagle's medium (DMEM; Gibco; Thermo Fisher Scientific, Inc., Waltham, MA, USA) supplemented with penicillin (100 U/ml, Sigma-Aldrich; Merck KGaA, Darmstadt, Germany), streptomycin sulfate $(100 \mu \mathrm{g} / \mathrm{ml}$, Sigma-Aldrich; Merck KGaA) and 10\% lot-selected fetal bovine serum (FBS; Hyclone; GE Healthcare Life Sciences, Logan, UT, USA) at $37^{\circ} \mathrm{C}$ in a $5 \% \mathrm{CO}_{2}$ humidified incubator. Following $72 \mathrm{~h}$ of adhesion, non-adherent cells were removed, whereas adherent cells were cultured for an additional 7 days with a single media change. The adherent cells were then harvested by trypsin digestion. The cells were centrifuged at $4^{\circ} \mathrm{C}, 1,000 \mathrm{x} \mathrm{g}$ for $5 \mathrm{~min}$, and then washed three times with PBS containing 0.3\% FBS (Hyclone; GE Healthcare Life Sciences). Cell aliquots $\left(1 \times 10^{6}\right)$ were incubated for $20 \mathrm{~min}$ at $4^{\circ} \mathrm{C}$ with phycoerythrin (PE; cat. no. 108107; concentration, $0.2 \mathrm{mg} / \mathrm{ml}$; dilution, 1:40), fluorescein isothiocyanate (FITC; cat. no. 102205; concentration, $0.5 \mathrm{mg} / \mathrm{ml}$; dilution, 1:50), peridinin chlorophyll protein (Per CP; cat. no. 202220; concentration, $0.2 \mathrm{mg} / \mathrm{ml}$; dilution, 1:20) and allophycocyanin (APC; cat. no. 201809; concentration, $0.2 \mathrm{mg} / \mathrm{ml}$; dilution, $1: 100$ ) -conjugated antibodies against mouse Sca-1, CD29, CD45 and CD11b, respectively (BioLegend, Inc., San Diego, CA, USA). Acquisition was performed on a fluorescence-activated cell sorting (FACS) device (Aria model; BD Biosciences, Franklin Lakes, NJ, USA) and analysis was performed using FACS DIVE software, version 6.1.3 (BD Biosciences). The sorted CD29 $9^{+}$, Sca- $1^{+}, \mathrm{CD} 45^{-}$and CD11b cells were cultured further in DMEM (containing penicillin, streptomycin sulfate and $10 \%$ FBS) for enrichment.

Isolation and characterization of murine bone marrow EPCs. Bone marrow EPCs were collected and cultured using the same technique as for bone marrow MSCs. Cell aliquots were incubated for $20 \mathrm{~min}$ at $4^{\circ} \mathrm{C}$ with the following anti-mouse antibodies: CD11b-APC conjugated (cat. no. 201809; concentration, $0.2 \mathrm{mg} / \mathrm{ml}$; dilution, 1:100; BioLegend, Inc.), CD31-FITC conjugated (cat. no. 102506; concentration, $0.5 \mathrm{mg} / \mathrm{ml}$; dilution, 1:50; BioLegend, Inc.), CD144-Per CP conjugated (cat. no. 46-1441-82; concentration, $0.2 \mathrm{mg} / \mathrm{ml}$; dilution, 1:50; BioLegend, Inc.) and CD133-PE conjugated (cat. no. 141203; concentration, $0.2 \mathrm{mg} / \mathrm{ml}$; dilution, 1:40; BioLegend, Inc.). Acquisition was performed using a FACS device (Aria model; BD Biosciences) and analysis was performed using FACS DIVE software, version 6.1.3 (BD Biosciences). The sorted $\mathrm{CD} 33^{+}, \mathrm{CD} 31^{+}, \mathrm{CD}_{144^{+}}$and $\mathrm{CD} 11 \mathrm{~b}^{-}$cells were cultured further in EBM-2 medium (Lonza, Inc., Walkesville, MD, USA) for enrichment; EPCs were cultured and seeded in this media for all subsequent experiments.

Co-culture of EPCs and MSCs in a transwell system. For the co-culture of EPCs and MSCs, a $6.5 \mathrm{~mm}, 24$-well Transwell system with $0.4 \mu \mathrm{m}$ pore polycarbonate membrane inserts (Corning Incorporated, Corning, NY, USA) was used. Third-passage MSCs and EPCs were seeded $\left(5 \times 10^{4}\right.$ cells) at a 1:1 ratio into the Transwell system. In the experimental group, the EPCs were seeded into the lower chamber, whereas the MSCs were seeded into the upper chamber. In the control group, only the EPCs were seeded, no MSCs were seeded into the upper chamber, at the same density as in the experimental group, into the lower chamber.

5-bromo-2'-deoxyuridine (BrdU) assay. EPCs $\left(1.5 \times 10^{5}\right.$ cells/dish) were seeded into a $35 \mathrm{~mm}$ dish with $2 \mathrm{ml} 0.4 \%$ fetal bovine serum and were cultured for $72 \mathrm{~h}$ at $37^{\circ} \mathrm{C}$ in an atmosphere containing $5 \% \mathrm{CO}_{2}$. Subsequently, $40 \mu \mathrm{l} \mathrm{BrdU}$ solution ( $500 \mu \mathrm{mol}$; Sigma-Aldrich; Merck KGaA) was pipetted directly onto the EPCs, which were incubated for an additional $40 \mathrm{~min}$ at $37^{\circ} \mathrm{C}$. The cells were washed three times in PBS containing $0.5 \%$ inactivated fetal calf serum (IFS; heated for $30 \mathrm{~min}$ in a $56^{\circ} \mathrm{C}$ water bath prior to use; Gibco; Thermo Fisher Scientific, Inc.), were treated with $2 \mathrm{~mol} \mathrm{HCl}$ for $5 \mathrm{~min}$ at $37^{\circ} \mathrm{C}$ and were then blocked with $0.5 \%$ IFS for $20 \mathrm{~min}$ at room temperature. Subsequently, the cells were incubated in serum-free medium with a rat anti-BrdU antibody (cat. no. ab152095; dilution, 1:50; Abcam, Cambridge, UK) for $2 \mathrm{~h}$ at $37^{\circ} \mathrm{C}$. A secondary rabbit anti-mouse immunoglobulin $\mathrm{G}$ antibody (dilution, 1:10,000; Vector Laboratories, Inc., Burlingame, CA, USA ) was applied for a further $1 \mathrm{~h}$ at $37^{\circ} \mathrm{C}$. The cells were incubated with peroxidase-conjugated streptavidin-horseradish peroxidase (Sigma-Aldrich; Merck KGaA) for $1 \mathrm{~h}$ at $37^{\circ} \mathrm{C}$ and were then stained with $0.05 \%$ 3,3'-diaminobenzidine (DAB; Sigma-Aldrich; Merck KGaA) and hematoxylin (Sigma-Aldrich; Merck KGaA). The BrdU-positive cells in 10 randomly selected high-power fields were counted under a light microscope (Olympus IX71; Olympus Corporation, Tokyo, Japan).

MTT assay. EPC proliferation was determined using MTT assay (Sigma-Aldrich; Merck KGaA). The EPCs were incubated for $12 \mathrm{~h}$ at $37^{\circ} \mathrm{C}$ prior to treatment with IGF-1. The EPCs were seeded into 24-well plates at a density of $1.5 \times 10^{4}$ cells/well and $0.5 \mathrm{ml}$ of various concentrations of IGF-1 (20, 50, 100 and $200 \mathrm{ng} / \mathrm{ml}$; Peprotech, Inc., Rocky Hill, NJ, USA) were added for $72 \mathrm{~h}$ at $37^{\circ} \mathrm{C}$. The control group was treated with PBS only. Subsequently, $50 \mu 1$ MTT $(5 \mathrm{mg} / \mathrm{ml})$ was added to each dish prior to incubation at $37^{\circ} \mathrm{C}$ for $4 \mathrm{~h}$, after which, $500 \mu 1$ dimethyl sulfoxide was added and the solution was oscillated for $10 \mathrm{~min}$. Absorbance was measured at $570 \mathrm{~nm}$ 
using a microplate reader (Bio-Rad Model 3550-UV; GMI Inc., Ramsey, MN, USA). The experiments were performed in triplicate and repeated three times.

ELISA to determine the expression of IGF-1 in the culture media of MSCs and EPCS. MSCs and EPCs $\left(1 \times 10^{6}\right.$ cells/dish) were seeded into a $60 \mathrm{~mm}$ dish with $4 \mathrm{ml}$ factor-free medium (EBM-2 without FBS), and were cultured for $24 \mathrm{~h}$ at $37^{\circ} \mathrm{C}$ in an atmosphere containing $5 \% \mathrm{CO}_{2}$. The culture media were then collected and centrifuged $\left(4^{\circ} \mathrm{C} ; 5,000 \mathrm{x} \mathrm{g} ; 10 \mathrm{~min}\right)$. The release of IGF-1 was then determined by ELISA assay (cat. no. SEA050Mu; USCN Life Sciences, Inc., Wuhan, China), according to the manufacturer's protocol. The absorbance was measured at $450 \mathrm{~nm}$ (minus the $690 \mathrm{~nm}$ absorbance background measurement) using a microplate reader (Bio-Rad Model 3550-UV; GMI Inc.).

IGF-1 small interfering (si)RNA and IGF-1 receptor (R) siRNA transfection assays, and neutralizing the effect of $I G F-1$. The MSCs and EPCs were suspended in $0.05 \%$ trypsin and $0.02 \%$ EDTA (Gibco; Thermo Fisher Scientific, Inc.). Subsequently, $1 \times 10^{6}$ cells in $2 \mathrm{ml}$ antibiotic-free medium were seeded into a $60 \mathrm{~mm}$ dish and grown for $24 \mathrm{~h}$ to $90 \%$ confluence. The following transfection reagents were used: Lipofectamine 2000 (Invitrogen; Thermo Fisher Scientific, Inc.), Opti-MEM (Invitrogen; Thermo Fisher Scientific, Inc.) reduced serum medium, IGF-1 receptor (IGF-1R) siRNA (cat. no. 159115; Invitrogen; Thermo Fisher Scientific, Inc.), IGF-1 siRNA (cat. no. sc-37194; Santa Cruz Biotechnology, Inc., Dallas, TX, USA) and control siRNA (FITC conjugate)-A (cat. no. sc-36869; Santa Cruz Biotechnology, Inc.). The MSCs and EPCs were transfected with $13 \mathrm{nM}$ IGF-1 siRNA and IGF-1R siRNA. The siRNA control group was transfected with $13 \mathrm{nM}$ control siRNA (FITC conjugate)-A. The mock group was transfected with Lipofectamine 2000, instead of siRNA, according to the manufacturer's protocols, in order to visualize how effectively siRNAs were delivered to the MSCs and EPCs. The transfection procedure was performed in $60 \mathrm{~mm}$ culture dishes, which contained $2 \mathrm{ml}$ medium/dish (DMEM+10\% FBS; $1 \times 10^{6}$ cells/dish), as follows: In separate RNase-/DNase-free tubes, $13 \mu \mathrm{l}$ siRNA or $10 \mu \mathrm{l}$ Lipofectamine 2000 was added to $200 \mu \mathrm{l}$ Opti-MEM reduced serum, respectively, and the mixtures were incubated for $5 \mathrm{~min}$ at room temperature. Subsequently, the mixtures were combined and incubated at room temperature for an additional $15 \mathrm{~min}$, and were then added to the dish for $48 \mathrm{~h}$ transfection. Post-transfection, the mixture was replaced with fresh complete culture medium for a further $24 \mathrm{~h}$. Neutralization of IGF-1 in the MSC and EPC culture media was performed using $1.0 \mu \mathrm{g} / \mathrm{ml}$ anti-IGF-1 (cat. no. ab9572; Abcam) for $48 \mathrm{~h}$ at $37^{\circ} \mathrm{C}$. The experiments were performed in duplicate and repeated three times.

Reverse transcription-quantitative polymerase chain reaction (RT-qPCR) analysis. The EPCs were cultured $\left(1 \times 10^{6} \mathrm{cells} / \mathrm{dish}\right)$ in serum- and factor-free medium (EBM-2 without FBS) for $24 \mathrm{~h}$ and then divided into three groups: i) EPCs only; ii) EPCs treated with $100 \mathrm{ng} / \mathrm{ml} \mathrm{IGF-1} \mathrm{for} 72 \mathrm{~h}$; and iii) EPCs treated with $10 \mu \mathrm{M}$ LY294002 (Sigma-Aldrich; Merck KGaA) for $1 \mathrm{~h}$, and then $100 \mathrm{ng} / \mathrm{ml} \mathrm{IGF-1} \mathrm{was} \mathrm{added} \mathrm{for} 72 \mathrm{~h}$ at $37^{\circ} \mathrm{C}$. The total RNA was extracted from the EPCs using TRIzol reagent (cat. no. 15596026; Invitrogen; Thermo Fisher Scientific, Inc.), according to the manufacturer's instructions, and the purity of RNA was determined using the ratio of absorbance readings at $280 \mathrm{~nm}$ (A280, Nanodrop 2000; Thermo Fisher Scientific, Inc.), with ratios within 1.8-2.0 considered appropriate for cDNA synthesis. Total RNA (200 ng) was reverse-transcribed using the RevertAid ${ }^{\text {Tit }}$ H Minus First Strand cDNA Synthesis kit (cat. no. K1632; Fermentas, Thermo Fisher Scientific, Inc.), according to the manufacturer's instructions. The mRNA expression levels were determined by RT-qPCR using the SYBR ${ }^{\circledR}$-Green PCR Master mix (cat. no. 208054; Qiagen $\mathrm{GmbH})$, according to the manufacturer's instructions. The thermocycling conditions were as follows: $95^{\circ} \mathrm{C}$ for $2 \mathrm{~min}$, then 40 cycles of $95^{\circ} \mathrm{C}$ for $30 \mathrm{sec}$ and $60^{\circ} \mathrm{C}$ for $20 \mathrm{sec}$. The reaction included $10 \mu \mathrm{l} \mathrm{SYBR}^{\circledR}$ Green PCR mix, $2 \mu \mathrm{l}$ primers, $2 \mu \mathrm{lcDNA}$ $(500 \mathrm{ng})$ and $6 \mu \mathrm{l}$ DNase/RNase free water to a final reaction volume of $20 \mu \mathrm{l}$. The results were analyzed using Bio-Rad CFX96 Manager software version 3.1 (Bio-Rad Laboratories, Inc., Hercules, CA, USA). Data were collected following each annealing step. $\beta$-actin was used as an endogenous control to correct for differences in the amounts of total RNA in each sample. The primer sequences and the sizes of the amplified fragments were as follows: IGF-1R (277 bp), forward 5'-GTC GAAGAATCGCATCATCA-3', reverse 5'-GCATCCTGC CCATCATACTC-3'; and $\beta$-actin (174 bp), forward 5'-GTG CTA TGT TGC TCT AGA CTT CG-3' and reverse 5'-ATG CCA CAG GAT TCC ATA CC-3'. The experiments were performed in triplicate and repeated three times. Results were quantified using the $2^{-\Delta \triangle C q}$ method (18).

Western blot analysis. The EPCs were cultured $\left(1 \times 10^{6}\right.$ cells/dish) in factor-free medium (EBM-2 without FBS) for $24 \mathrm{~h}$ and were then divided into three groups: i) EPCs only; ii) EPCs treated with $100 \mathrm{ng} / \mathrm{ml} \mathrm{IGF-1} \mathrm{for} 72 \mathrm{~h}$; and iii) EPCs treated with $10 \mu \mathrm{M}$ LY294002 (Sigma-Aldrich; Merck KGaA) for $1 \mathrm{~h}$, and then $100 \mathrm{ng} / \mathrm{ml}$ IGF-1 was added for $72 \mathrm{~h}$ at $37^{\circ} \mathrm{C}$. Protein samples were extracted from the EPCs using radioimmunoprecipitation assay buffer (Thermo Fisher Scientific, Inc.) containing phenylmethylsulfonyl fluoride (Thermo Fisher Scientific, Inc.) and Phosphatase Inhibitor Cocktail (Sigma-Aldrich; Merck KGaA). Protein concentration was measured using the bicinchoninic acid method (Thermo Fisher Scientific, Inc.) and samples $(40 \mu \mathrm{g})$ were run on a $10 \%$ SDS-PAGE gel. Following transferal to a polyvinylidene fluoride membrane, the blots were treated according to the standard procedure [electrophoresis $(120 \mathrm{~V}$, $90 \mathrm{~min}$ ), transfer to $300 \mathrm{~mA}$ film, $3 \%$ bovine serum albumin (cat. no. V900933; Sigma-Aldrich; Merck KGaA) treatment for $1 \mathrm{~h}$ at room temperature]. The blots were initially incubated at $4^{\circ} \mathrm{C}$ overnight with phosphorylated (p)-Akt (cat. no. \#4060; 1:1,000; Cell Signaling Technology, Inc., Danvers, MA, USA), total (t)-Akt (cat. no. \#2920; 1:1,000; Cell Signaling Technology, Inc.) and $\beta$-actin primary antibodies (cat. no. NB600-501; 1:5,000, Novus Biologicals, LLC, Littleton, CO, USA). Following incubation for $2 \mathrm{~h}$ at room temperature with rabbit anti-mouse (cat. no. sc-358914; dilution, 1:10,000) or goat anti-rabbit (cat. no. sc-2004; dilution, 1:7,000) peroxidase-conjugated secondary antibodies (Santa Cruz Biotechnology Inc.), the blots were developed using enhanced chemiluminescence (GE Healthcare Bio-Sciences, 
A
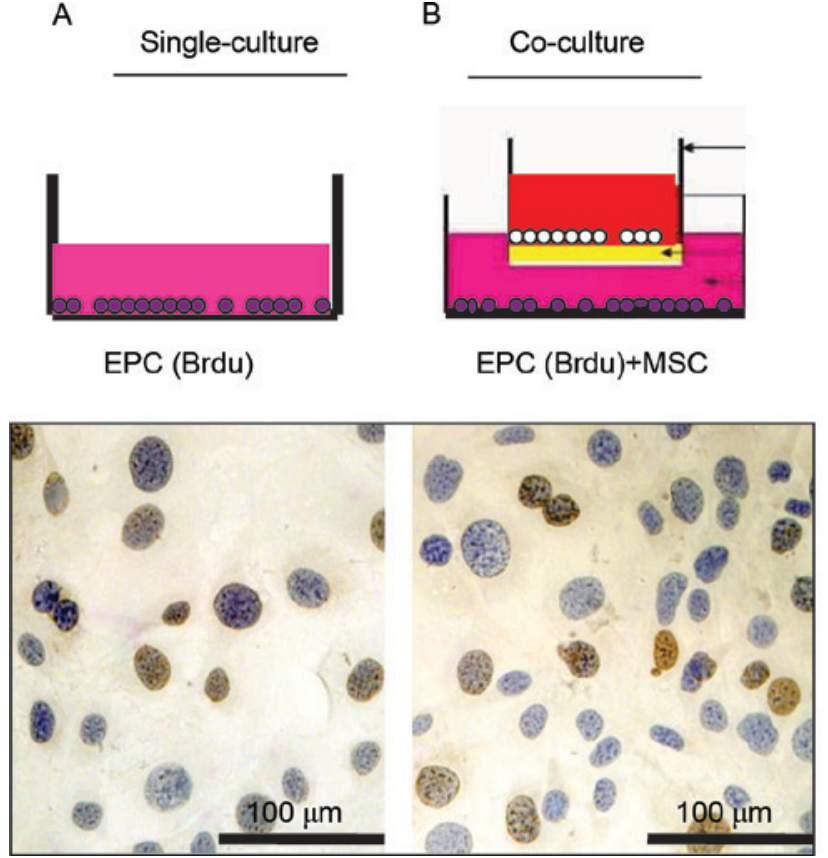
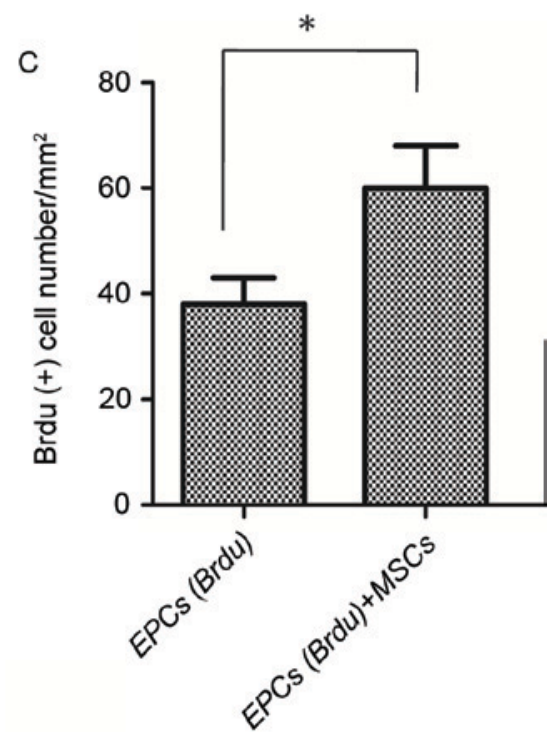

Figure 1. MSCs promoted EPC proliferation in vitro, as determined by co-culture. (A and B) EPCs were identified by DAB (blue) staining, whereas EPCs in the DNA-synthesis phase were counterstained with BrdU (brown). White dots indicate MSCs and purple dots indicate EPCs. (C) Number of BrdU-positive cells in the experimental group was significantly higher compared with in the control group. ${ }^{*} \mathrm{P}<0.05$. MSCs, mesenchymal stem cells; EPCs, endothelial progenitor cells; DAB, 3,3'-diaminobenzidine; BrdU, 5-bromo-2'-deoxyuridine.

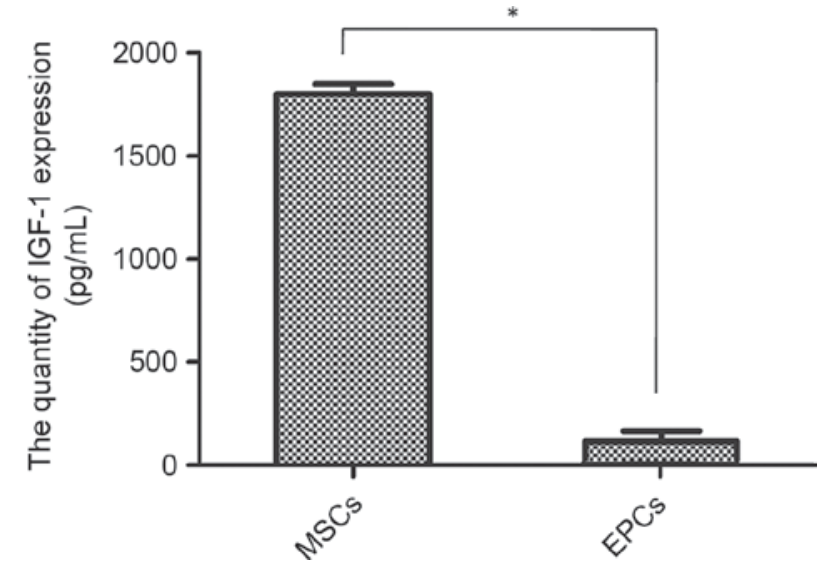

Figure 2. Expression of IGF-1 in the culture media of MSCs and EPCs. The expression of IGF-1 was significantly higher in MSCs compared with in EPCs, as determined by ELISA. Statistical significance was determined by Student's t-test ("P<0.01). IGF-1, insulin-like growth factor 1; MSCs, mesenchymal stem cells; EPCs, endothelial progenitor cells.

Pittsburgh, PA, USA). Gel-Pro Analyzer version 4.0 (Media Cybernetics, Inc., Rockville, MD, USA) was used to analyze the western blot results and the integrated optical density was acquired. The experiments were performed in triplicate and repeated three times.

Statistical analysis. Statistical analyses were conducted using SPSS for Windows, version 17.0 (SPSS Inc., Chicago, IL, USA). Results are expressed as the mean \pm standard deviation. Statistical significance was assessed using Student's unpaired t-test or two-way analysis of variance followed by Tukey and $\chi^{2}$ tests. $\mathrm{P}<0.05$ was considered to indicate a statistically significant difference.

\section{Results}

Promotion of EPC proliferation in vitro by MSCs. As presented in Fig. 1A and B, EPCs were identified by DAB (blue) staining, whereas EPCs in the DNA-synthesis phase were counterstained with BrdU (brown). As demonstrated in Fig. 1C, the total number of BrdU-positive cells in the experimental group was significantly higher compared with in the control group $(\mathrm{P}<0.05)$, significance was determined using Student's t-test. These data indicated that MSCs may promote EPC proliferation in vitro.

Expression levels of IGF-1 in MSCs and EPCs. According to the literature, IGF-1 is associated with the proliferation of other cells (19-21). Therefore, it was hypothesized that IGF-1 may serve an important function in MSC-mediated EPC proliferation. To validate this hypothesis, the expression levels of IGF-1 in the culture media of MSCs (cultured in factor-free medium) was detected by ELISA. To eliminate autocrine effects on EPC proliferation the expression of IGF-1 was also detected in the culture media of EPCs. As demonstrated in Fig. 2, the expression levels of IGF-1 were significantly higher in MSCs compared with in EPCs $(1,857.62 \pm 49.56$ vs. $168.94 \pm 5.21 \mathrm{pg} / \mathrm{ml} ; \mathrm{P}<0.01)$.

Effects of IGF-1 on EPC proliferation in vitro. The effects of IGF-1 on the proliferation of EPCs were examined, and the signaling pathway underlying the regulatory effects was analyzed. Initially, alterations in the number and absorbance value of EPCs following treatment with various concentration of IGF-1 (20-200 ng/ml) for $72 \mathrm{~h}$ were examined. As demonstrated in Fig. 3A and B, IGF-1 increased the number and absorbance value of EPCs in a concentration-dependent 
A

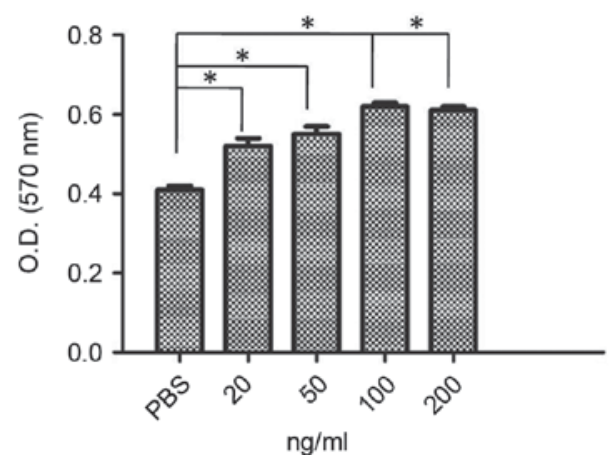

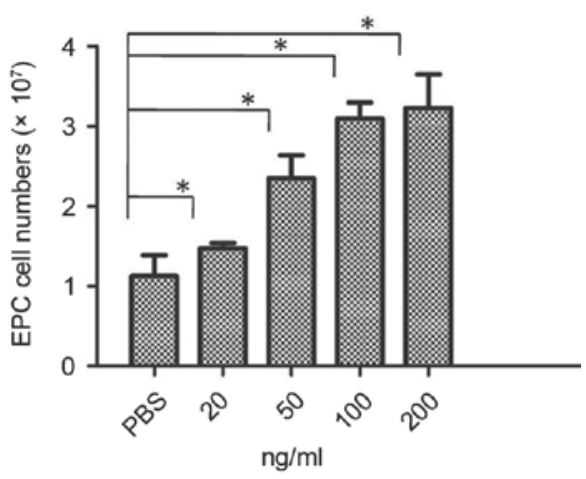

Figure 3. Effects of various concentrations of IGF-1 on EPC proliferation, as determined by MTT assay and cell count. (A) IGF-1 (20,50, $100 \mathrm{and} 200 \mathrm{ng} / \mathrm{ml})$ increased the absorbance values of EPCs. (B) IGF-1 (20,50, 100 and $200 \mathrm{ng} / \mathrm{ml})$ increased the number of EPCs. "P<0.05. IGF-1, insulin-like growth factor 1; EPCs, endothelial progenitor cells; O.D., optical density.

A

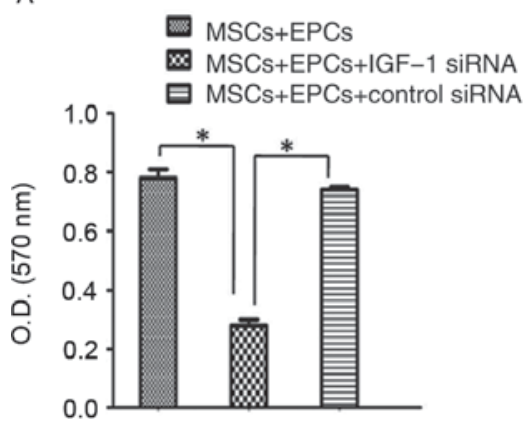

B

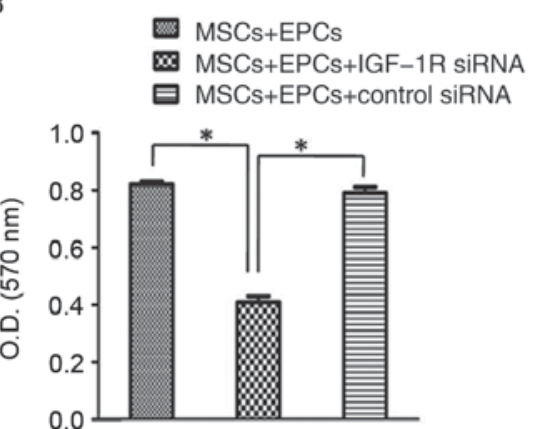

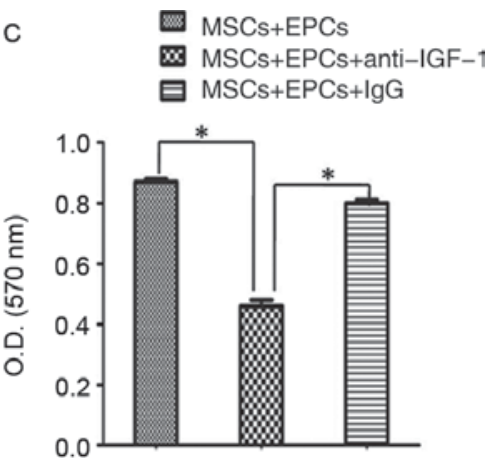

Figure 4. Effects of IGF-1 on EPC proliferation in vitro. (A) MSCs + EPCs; MSCs + EPCs + IGF-1 siRNA; MSCs + EPCs+control siRNA. (B) MSCs + EPCs; MSCs + EPCs + IGF-1R siRNA; MSCs + EPCs + control siRNA. (C) MSCs + EPCs; MSCs + EPCs+anti-IGF-1; MSCs + EPCs + IgG. The results demonstrated that the proliferation of EPCs was reduced in the treatment groups compared with in the control group. " $\mathrm{P}<0.05$. IGF-1, insulin-like growth factor 1 ; EPCs, endothelial progenitor cells; MSCs, mesenchymal stem cells; siRNA, small interfering RNA; O.D., optical density; IgG, immunoglobulin G.

manner $(\mathrm{P}<0.05)$. As the higher concentration of $100 \mathrm{ng} / \mathrm{ml}$ IGF-1 produced a significant effect, in subsequent experiments, EPCs received $100 \mathrm{ng} / \mathrm{ml}$ of IGF-1.

Subsequently, the following experiments were conducted: i) Transfection of MSCs with IGF-1 siRNA; ii) transfection of EPCs with IGF-1R siRNA; and, iii) neutralization of IGF-1 in the cultured media of MSCs and EPCs with anti-IGF-1. The results demonstrated that the proliferation of EPCs was attenuated in the IGF-1 siRNA transfection group compared with in the control group $(\mathrm{P}<0.05$; Fig. 4A). In the EPCs transfected with IGF-1R siRNA, the expression of IGF-1R on the surface was blocked and the proliferation of EPCs was reduced $(\mathrm{P}<0.05$; Fig. 4B). Furthermore, neutralizing the effects of IGF-1 reduced the proliferation of EPCs $(\mathrm{P}<0.05$; Fig. 4C). These findings indicated that IGF-1 may serve an important function in the MSC-mediated proliferation of EPCs.

Activation of PI3K/Akt signaling pathway by IGF-1. To reveal whether the PI3K/Akt signaling pathway was involved in IGF-1-inducedEPC proliferation, the effects of IGF-1 combined with the specific pharmacological inhibitor LY294002 were investigated. The control group consisted of untreated EPCs. The remaining two groups were each treated with $100 \mathrm{ng} / \mathrm{ml}$ IGF-1, with one group treated with LY294002 prior to IGF-1 treatment. As demonstrated in Fig. 5, the absorbance value of
EPCs was significantly decreased following treatment with the inhibitor. Although the addition of IGF-1 enhanced EPC proliferation, treatment with the PI3K/Akt inhibitor resulted in a significant attenuation of the IGF-1-dependent cell proliferation $(\mathrm{P}<0.05)$.

In mammals, the combination of IGF-1 and IGF-1R initiates a downstream signal transduction pathway, activating a transcription factor by transducing the extracellular signals into the nucleus (21). Therefore, RT-qPCR was used to detect the mRNA expression levels of IGF-1R; the results demonstrated that IGF-1R mRNA expression was increased in response to IGF-1 treatment and the specific inhibitor of PI3K, LY294002, did not inhibit the expression of IGF-1R mRNA. (Fig. 6).

The expression levels of $\mathrm{p}$-Akt and $\mathrm{t}$-Akt protein were measured by western blot analysis, with the expression of $\beta$-actin used as the control. To test the role of PI3K/Akt in IGF-1 mediated EPCs proliferation, the specific inhibitor of PI3K, LY294002, was used to reveal the inhibitory effects. The results demonstrated that Akt phosphorylation (Thr-308) was increased in EPCs following treatment with IGF-1, whereas the presence of LY294002 offset this effect (Fig. 7A). By examining the effects of blocking the PI3K/Akt signaling pathway on protein expression, it was confirmed that the IGF-1-induced expression of p-Akt was considerably attenuated by pretreatment with the inhibitor (Fig. 7B). These 


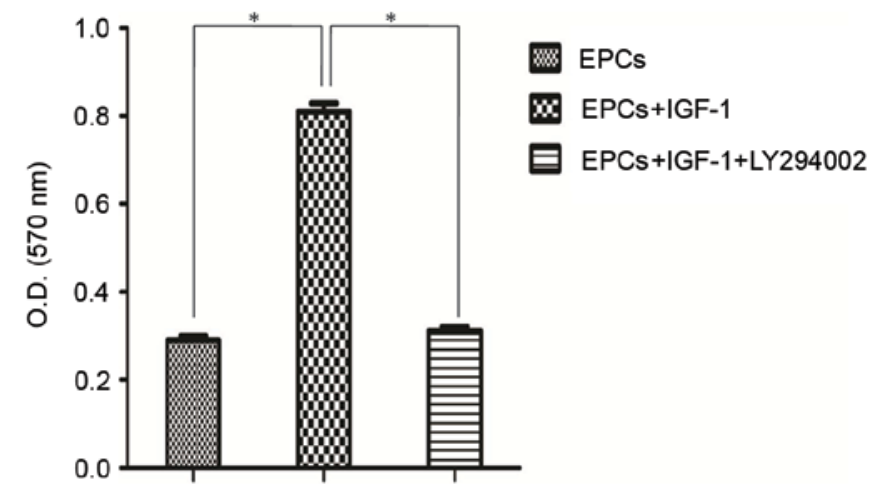

Figure 5. Inhibition of EPC proliferation by LY294002, as determined by MTT assay. The inhibitor LY294002 was added to the EPCs prior to treatment with IGF-1. The results demonstrated that the proliferation of EPCs was reduced following treatment with the inhibitor, whereas the addition of IGF-1 enhanced EPC proliferation. ${ }^{*} \mathrm{P}<0.05$. EPCs, endothelial progenitor cells; IGF-1, insulin-like growth factor 1; O.D., optical density.

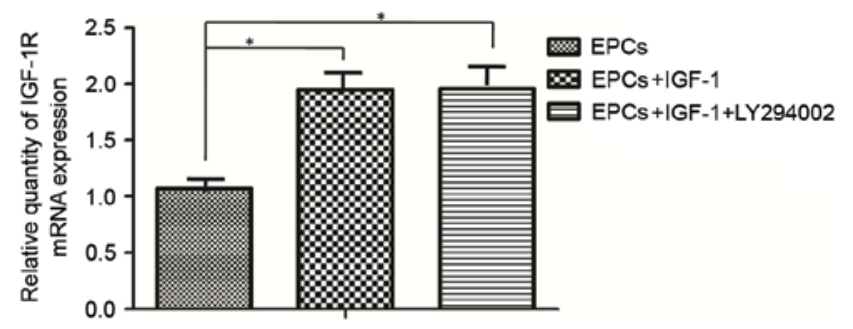

Figure 6. Expression of IGF-1R mRNA, as determined by reverse transcription-quantitative polymerase chain reaction. IGF-1 increased the mRNA expression levels of IGF-1R in EPCs. The specific inhibitor of PI3K, LY294002, did not inhibit the expression of IGF-1R mRNA. "P<0.05. IGF-1R, insulin-like growth factor 1 receptor; EPCs, endothelial progenitor cells.

results confirmed the involvement of the PI3K/Akt signaling pathway in IGF-1-mediated EPC proliferation.

\section{Discussion}

IGF-1 can promote mammalian cell proliferation and is conducive to the growth of organisms $(20,22,23)$. In mammals, the combination of IGF-1 and IGF-1R initiates a downstream signal transduction pathway, activating a transcription factor by transducing the extracellular signals into the nucleus. Therefore, IGF-1 is considered to serve an important role in various biological effects, including cell proliferation, promotion and apoptotic inhibition $(21,24,25)$. Li et al (19) reported that the age-associated decrease in IGF-1 levels resulted in dysfunctional EPCs, whereas IGF-1 was able to enhance EPC proliferation. Recently, considerable progress has been made in understanding the specific IGF-1 downstream signaling pathways mediating protein synthesis (26).

Our previous study (9) demonstrated that MSCs had an extensive and close association with EPCs; MSCs were able to promote EPC proliferation and EPCs enhanced MSC self-renewal. Fedorovich et al (27) demonstrated that EPCs derived from peripheral blood contributed to the osteogenic differentiation of MSCs in vitro, and MSCs supported EPC proliferation and stabilized the formed cellular networks (27). The present study indicated that MSCs could promote EPC proliferation; however,
A
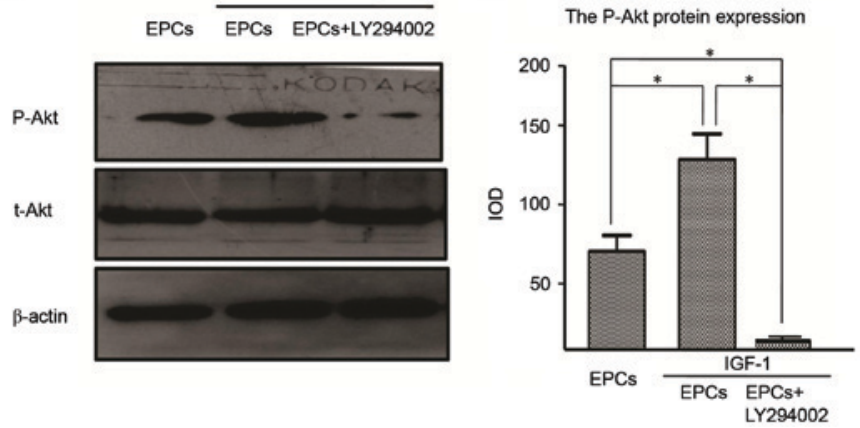

Figure 7. Involvement of PI3K/Akt activation in IGF-1-mediated EPC proliferation. (A) EPCs were pretreated with LY294002 prior to IGF-1 treatment. Subsequently, the phosphorylation level of Akt was measured by western blot analysis. (B) Semi-quantification analysis of western blotting results demonstrated that p-Akt protein expression was lower in the LY294002-treated group compared with the other groups Conversely, p-Akt protein expression was increased in EPCs treated with IGF-1 compared with the other groups. ${ }^{*} \mathrm{P}<0.05$. PI3K, phosphatidylinositol 3-kinase; Akt, protein kinase B; p, phosphorylated; t, total; IGF-1, insulin-like growth factor 1; EPCs, endothelial progenitor cells; IOD, integrated optical density.

the mechanisms underlying the MSC-induced activation of EPC proliferation remain poorly understood. To reveal the molecular mechanisms regulating this process, the effects of IGF-1, which is secreted by MSCs, on EPC proliferation via the PI3K/Akt signaling pathway were examined.

In the present study, EPCs were treated with various doses of IGF-1 and the proliferative capabilities of treated EPCs were detected by MTT assay. The results demonstrated that IGF-1 could significantly promote the proliferation of EPCs in vitro. To further explore the signaling pathways involved in EPC proliferation, the small molecule inhibitor LY294002 was used to block the PI3K/Akt pathway. Subsequently, the IGF-1-mediated alterations in EPC proliferation were detected. The results indicated that the use of LY294002 had a significant inhibitory effect on EPC proliferation despite treatment with IGF-1. Furthermore, IGF-1 was able to increase the mRNA expression levels of IGF-1R in EPCs, thus indicating that the PI3K/Akt signaling pathway was involved in IGF-1 and IGF-1R-induced EPC proliferation.

The primary signaling pathway hypothesized to be associated with IGF-1 is PI3K activation, which is involved in various cellular processes, including protection from apoptosis and promotion of proliferation via Akt activation. Inhibition of PI3K signaling prevents cell cycle completion in cultured satellite cells by inducing cell cycle arrest in $\mathrm{G}_{1}$ phase, thus reducing cell proliferation. The PI3K signaling pathway has been suggested to be important under certain conditions for the continuance of cell proliferation, but not for cell differentiation (28). In addition, IGFs can activate the target of rapamycin signaling pathway by inducing the PI3K/Akt signaling pathway (29).

In conclusion, the results of the present study demonstrated that the phosphorylation of Akt was significantly increased in the presence of IGF-1 compared with in the control group, whereas treatment with the inhibitor offset the effects of IGF-1 on EPCs. These findings indicated that IGF-1 may exert proliferative effects on EPCs via the PI3K/Akt signaling pathway. 
Activation of the PI3K/Akt pathway leads to the altered transcription of genes involved in the cell cycle, thus accelerating cell cycle progression upon stimulation by IGF-1. These results suggested that IGF-1-induced EPC proliferation occurs via the PI3K/Akt signaling pathway. Clarifying the effect of IGF-1 on EPCs proliferation via the PI3K/Akt signaling pathway, may provide a novel strategy to treat vascular diseases in cell transplantation.

\section{Acknowledgements}

The present study was supported by grants from the National Natural Science Foundation of China (grant no. 31271458), the Science and Technology Program of Xinjiang Production and Construction Corps (grant no. 2014AB047), the Scientific Research Foundation for returned overseas Chinese scholars, Ministry of Human Resources and Social Security of the People's Republic of China (grant no. RSLX201201) and Shihezi University youth science and technology research and development program, basis and application research project (grant no. 20142RKXYQ20).

\section{References}

1. Friedenstein AJ , Chailakhyan RK and Gerasimov UV: Bone marrow osteogenic stem cells: In vitro cultivation and transplantation in diffusion chambers. Cell Tissue Kinet 20: 263-272, 1987.

2. Bruder SP, Jaiswal N and Haynesworth SE: Growth kinetics, self-renewal, and the osteogenic potential of purified human mesenchymal stem cells during extensive subcultivation and following cryopreservation. J Cell Biochem 64: 278-294, 1997.

3. Jiang Y, Jahagirdar BN, Reinhardt RL, Schwartz RE, Keene CD, Ortiz-Gonzalez XR, Reyes M,Lenvik T, Lund T, Blackstad M, et al: Pluripotency of mesenchymal stem cells derived from adult marrow. Nature 418: 41-49, 2002.

4. Bianco P, Robey PG and Simmons PJ: Mesenchymal stem cells: Revisiting history, concepts, and assays. Cell Stem Cell 2: 313-319, 2008.

5. Moore KA and Elmendorf SC: Propagule vs. niche limitation: Untangling the mechanisms behind plant species' distributions. Ecol Lett 9: 797-804, 2006.

6. Timmermans F,Plum J, Yöder MC,Ingram DA, Vandekerckhove B and Case J: Endothelial progenitor cells: Identity defined? J Cell Mol Med 13: 87-102, 2009.

7. Werner N, Junk S, Laufs U, Link A, Walenta K, Bohm M and Nickenig G: Intravenous transfusion of endothelial progenitor cells reduces neointima formation following vascular injury. Circ Res 93: e17-e24, 2003.

8. Atluri P, Miller JS, Emery RJ, Hung G, Trubelja A, Cohen JE, Lloyd K, Han J, Gaffey AC, MacArthur JW, et al: Tissue engineered, hydrogel-based endothelial progenitor cell therapy robustly revascularizes ischemic myocardium and preserves ventricular function. J Thorac Cardiovasc Surg 148: 1090-1098, 2014.

9. Zhang H, Xian L, Lin Z, Yang C, Zhang M, Feng W, Peng X, Chen $\mathrm{X}$ and $\mathrm{Wu} \mathrm{X}$ : Endothelial progenitor cells as a possible component of stem cell niche to promote self-renewal of mesenchymal stem cells. Mol Cell Biochem 397: 235-243, 2014.

10. Cao X, Wu X, Frassica D, Yu B, Pang L, Xian L, Wan M, Lei W, Armour M, Tryggestad E, et al: Irradiation induces bone injury by damaging bone marrow microenvironment for stem cells. Proc Natl Acad Sci 108: 1609-1614, 2011.

11. Kinnaird T, Stabile E, Burnett MS, Lee CW, Barr S, Fuchs S and Epstein SE: Marrow-derived stromal cells express genes encoding a broad spectrum of arteriogenic cytokines and promote in vitro and in vivo arteriogenesis through paracrine mechanisms. Circ Res 94: 678-685, 2004.

12. Nagaya $\mathrm{N}$, Kangawa $\mathrm{K}$, Itoh $\mathrm{T}$, Iwase $\mathrm{T}$, Murakami $\mathrm{S}$, Miyahara Y, Fujii T, Uematsu M, Ohgushi H, Yamagishi M, et al: Transplantation of mesenchymal stem cells improves cardiac function in a rat model of dilated cardiomyopathy. Circulation 112 $1128-1135,2005$
13. Noguchi S: The biological function of insulin-like growth factor-I in myogenesis and its therapeutic effect on muscular dystrophy. Acta Myol 24: 115-118, 2005.

14. hen Z, Seyfert HM, Löhrke B, Schneider F, Zitnan R, Chudy A, Kuhla S, Hammon HM, Blum JW, Martens H, et al: An energy-rich diet causes rumen papillae proliferation associated with more IGF type 1 receptors and increased plasma IGF-1 concentrations in young goats. J Nutr 134: 11-17, 2004.

15. Sandri M, Barberi L, Bijlsma AY, Blaauw B, Dyar KA, Milan G, Mammucari C, Meskers CG, Pallafacchina G, Paoli A, et al: Signalling pathways regulating muscle mass in ageing skeletal muscle: The role of the IGF1-Akt-mTOR-FoxO pathway. Biogerontology 14: 303-323, 2013.

16. Liu M and Zhang S: Amphioxus IGF-like peptide induces mouse muscle cell development via binding to IGF receptors and activating MAPK and PI3K/Akt signalling pathways. Mol Cell Endocrinol 343: 45-54, 2011.

17. Wu X, Pang L, Lei W, Lu W, Li J, Li Z, Frassica FJ, Chen X, Wan M and Cao X: Inhibition of Sca-1-positve skeletal stem cell recruitment by alendronate blunts the anabolic effects of parathyroid hormone on bone remodeling. Cell Stem Cell 7: 571-580, 2010.

18. Livak KJ and Schmittgen TD: Analysis of relative gene expression data using real-time quantitative PCR and the 2( Delta Delta C(T)) method. Methods 25: 402-408, 2001.

19. Li W, Yang SY, Hu ZF, Winslet MC, Wang W and Seifalian AM: Grow th factors enhance endothelial progenitor cell proliferation under high-glucose conditions. Med Sci Monit 15: BR357-BR363, 2009.

20. Shavlakadze T, Chai J, Maley K, Cozens G, Grounds G, Winn N, Rosenthal N and Grounds MD: A growth stimulus is needed for IGF-1 to induce skeletal muscle hypertrophy in vivo. J Cell Sci 123: 960-971, 2010

21. Bibollet-Bahena O and Almazan G: IGF-1-stimulated protein synthesis in oligodendrocyte progenitors requires PI3K/mTOR/Akt and MEK/ERK Pathways. J Neurochem 109: 1440-1451, 2009.

22. Blum JW and Baumrucker CR: Colostral and milk insulin-like growth factors and related substances: Mammary gland and neonatal (intestinal and systemic) targets. Domest Anim Endocrinol 23: 101-110, 2002.

23. Wang J, Zhu X, Li X, Wang W, Wang X, Liu L, Deng Q, Bai G, Wang J, Feng H, et al: Effects of copper on proliferation and autocrine secretion of insulin-like growth factor-1 (IGF-1) and IGF-binding protein-3 ( IGFBP-3) in chondrocytes from newborn pigs in vitro. Biol Trace Elem Res 144: 588-596, 2011.

24. Yu Y, Mu J, Fan Z, Lei G, Yan M, Wang S, Tang C, Wang Z, $\mathrm{Yu} \mathrm{J}$ and Zhang G: Insulin-like growth factor 1 enhances the proliferation and osteogenic differentiation of human periodontal ligament stem cells via ERK and JNK MAPK pathways. Histochem Cell Biol 137: 513-525, 2012.

25. Thum T, Hoeber S, Froese S, Klink I, Stichtenoth DO, Galuppo P, Jakob M, Tsikas D, Anker SD, Poole-Wilson PA, et al: Age-dependent impairment of endothelial progenitor cells is corrected by growth hormone mediated increase of insulin-like growth factor-1. Circ Res 100: 434-443, 2007.

26. Glass DJ: Skeletal muscle hypertrophy and atrophy signalling pathways. Int J Biochem Cell Biol 37: 1974-1978, 2005.

27. Fedorovich NE, Haverslag RT, Dhert WJ and Alblas J: The role of endothelial progenitor cells in prevascularized bone tissue engineering: Development of heterogeneous constructs. Tissue Eng Part A 16: 2355-2367, 2010.

28. Chakravarthy MV, Abraha TW, Schwartz RJ, Fiorotto ML and Booth FW: Insulin-like growth factor-I extends in vitro replicative life span of skeletal muscle satellite cells by enhancing G1/S cell cycle progression via the activation of phosphatidylinositol 3'-kinase/Akt signaling pathway. J Biol Chem 275: 35942-35952, 2000.

29. Glass DJ: PI3 kinase regulation of skeletal muscle hypertrophy and atrophy. Curr Top Microbiol Immunol 346: 267-278, 2010. 